\title{
EL DELITO DE PLAGIO: UNA PROPUESTA DE REGULACIÓN PENAL DE LA INFRACCIÓN AL DERECHO DE AUTOR*
}

\author{
Maria Alejandra Echavarría Arcila**
}

\begin{abstract}
Resumen
El plagio ha sido considerado como una de las infracciones más graves e intolerables a los derechos de autor, razón por la cual ha sido penalizado en diferentes ordenamientos jurídicos. No obstante, la falta de claridad sobre el concepto del plagio y su ilicitud ha generado incertidumbre e inseguridad jurídica en la creación y aplicación de la regulación penal de esta infracción a los derechos de autor. Como posible solución a esta problemática, en el presente escrito se propone un concepto técnico de plagio y una fórmula de tipo penal que lo describe y regula en su integridad, como infracción por antonomasia de las prerrogativas reconocidas al autor sobre su obra.
\end{abstract}

\section{Palabras clave}

Plagio, derecho de autor, propiedad intelectual, infracción de los derechos de autor, derecho penal.

\begin{abstract}
Plagiarism has been long considered one of the most serious and intolerable copyright infringements, this explaines why it has been penalized under different legal systems. However, the lack of clarity of the concept itself as well as its wrongfulness has created legal uncertainty in its criminal regulation. Therefore, as a possible solution to this problem, this paper proposes a technical concept of plagiarism and a complete definition of the criminal offense.
\end{abstract}

\footnotetext{
* El presente artículo sintetiza la propuesta central de la tesis de maestría presentada por la autora para optar al título de Magíster en Derecho con énfasis en Propiedad Intelectual en la Universidad Externado de Colombia, en el mes de enero del año 2014; tesis ésta que se titula "Plagio punible: regulación penal de la conducta constitutiva de plagio en Colombia".

* Candidata a Doctora en Gestión de la Tecnología y la Innovación de la Universidad Pontificia Bolivariana. Magíster en Derecho con énfasis en Propiedad Intelectual de la Universidad Externado de Colombia. Abogada de la Universidad Pontificia Bolivariana. Abogada del Centro de Propiedad Intelectual de la Universidad Pontificia Bolivariana y docente en pregrado y posgrado en materia de propiedad intelectual. Abogada de la firma Álvaro Vargas Abogados. Correo electrónico de contacto: mariaalejandra.echavarria@upb. edu.co.
} 


\section{Keywords}

Plagiarism, copyright, intellectual property, copyright infringement, criminal law.

\section{Introducción}

Nuestros antepasados no sólo tomaron la determinación de transmitir a la posteridad sus reflexiones, de modo inteligente y práctico, mediante las propuestas de sus comentarios con el fin de que no se perdieran, sino que además los fueron engrosando en cada momento publicándolos en volúmenes antiguos, y poco a poco llegaron a alcanzar la elegancia y la perfección de la ciencia.

$[\ldots]$

Sí debemos mostrar nuestra mayor gratitud a todos ellos, pero debemos censurar a quienes apropiándose de sus obras las publican como si fueran suyas, a quienes apoyándose en las investigaciones ajenas se vanaglorian profanando los escritos de otros autores con reprochable envidia: éstos merecen nuestra desaprobación y nuestra condena más severa, por su perversa manera de comportarse. La historia es testigo de que tales actitudes fueron castigadas escrupulosamente por los antiguos (Vitruvio, 1997).

En concordancia con la tendencia internacional relativa a la regulación penal del derecho de autor, diferentes ordenamientos jurídicos han consagrado tipos penales que sancionan las conductas atentatorias contra tales prerrogativas, dada su trascendencia para la salvaguarda y el estímulo de la actividad creativa y para el consecuente desarrollo cultural y económico del conglomerado social.

De antaño se ha considerado que el plagio es una de las infracciones más graves e intolerables contra los derechos de autor (Corte Suprema de Justicia, Sentencia No. 31403 de 2010), en la medida en que es un atentado de notoria recurrencia -aún en ámbitos académicos- que, además, vulnera prerrogativas tanto de contenido moral como patrimonial que, de manera originaria, son propias del creador de una obra.

Por esta razón, en diferentes latitudes se han propuesto fórmulas legislativas para penalizar y desincentivar esta conducta, ante los significativos y lesivos efectos que su comisión produce no sólo para el titular, sino, también, para la sociedad. No obstante, ante la ausencia de definiciones legales de esta infracción (particularmente en el ordenamiento jurídico colombiano), la misma se ha tornado en una vulneración polivalente, cuya regulación suele ser inversamente proporcional a su entendimiento.

¿Cómo debe entenderse la conducta constitutiva de plagio para efectos de su punición?, ¿cómo debe regularse penalmente esta infracción a los derechos de autor? En aras de resolver tales cuestionamientos, se propone a continuación una definición del fenómeno del plagio, para luego evaluar -con base en dicha nocióndiversos tipos penales que lo sancionan en otros ordenamientos; seguidamente, se presenta una propuesta para regular la referida conducta desde el derecho penal, que atienda a las especificidades del derecho de la propiedad intelectual. 


\section{Definición del plagio}

A pesar de que la conducta constitutiva del plagio ha sido pacíficamente reprochada, su definición no es igualmente coincidente y, por el contrario, ha supuesto una serie de contradicciones y vacíos legales, doctrinarios y jurisprudenciales, que devienen en una situación de inseguridad jurídica, con implicaciones que trascienden de lo teórico y se manifiestan en la práctica, dificultan el ejercicio de los derechos de autor y posibilitan la impunidad o, bien, la condena de inocentes.

Por lo anterior, resulta menester concretar el concepto de plagio punible, partiendo de que se trata de una infracción a los derechos de autor y, por ende, es un constructo propio de la disciplina jurídica de la propiedad intelectual, el cual debe atender a sus particularidades. En este sentido, es dable puntualizar que el plagio consiste en un acto complejo, tanto desde su ejecución, como desde sus consecuencias (Echavarría, 2014).

En efecto, en primer lugar, se postula que el plagio es un acto complejo desde su ejecución, en la medida en que -desde la perspectiva de su punición-comporta la realización cumulativa de tres diversas conductas por parte del sujeto activo: la copia, la apropiación y la utilización. Sólo cuando estas tres conductas se realizan de manera completa y concurrente se comete el acto complejo de plagio en el mundo fenomenológico.

Las referidas conductas de copia, apropiación y utilización se traducen, desde la imprescindible óptica de la propiedad intelectual, en el ejercicio indebido de derechos morales y patrimoniales de autor (que son conceptualizados y/o regulados en la normativa sobre propiedad intelectual), de conformidad con los cuales se definen las conductas en comento y se delimita el ámbito conductual típico del plagio.

Así, la copia, en sentido amplio, alude a la incorporación literal o simulada de todos o de algunos de los elementos originales de expresión que sean propios de una obra ajena y preexistente -que puede ser inédita o publicada y de cualquier tipo-, en una obra posterior que es atribuible al agente, quien debe ser una persona diferente del sujeto pasivo (Echavarría, 2014).

Por lo tanto, el objeto de la copia son los elementos que, por sí mismos o en su conjunto, constituyen una forma particular de expresión susceptible de protección por la vía del derecho de autor. Tales elementos pueden incorporarse de manera literal -plagio servil- o simulada -plagio inteligente- y ser todos los de la obra copiada - plagio total- o sólo algunos de ellos -plagio parcial-.

La apropiación, por su parte, se refiere al apoderamiento o usurpación de la autoría de los elementos originales contenidos en la obra ajena y preexistente, mediante alguna o algunas de las siguientes modalidades (Antequera, 2012): la indicación de un autor diferente del verdadero, la mención incidental o genérica del legítimo creador o la omisión de su identificación con usurpación de la paternidad (Echavarría, 2014). 
En este orden de ideas, el sujeto activo se apropia de la obra ajena y preexistente cuando la hace pasar por propia y ello tiene lugar, primero, al suplantar al legítimo autor de la misma de manera directa, atribuyéndose su autoría (esto es, indicando que es su creador); segundo, al no vincular de manera clara y concluyente al legítimo autor con su expresión creativa particular y, tercero, al no mencionar expresamente que el autor es otra persona, dando a entender, por las dos últimas vías mencionadas, que él es el creador, sin serlo.

Finalmente, la utilización consiste en cualquier uso o acto de explotación público (para efectos de relevancia y lesividad) de los elementos originales de la obra ajena copiada y apropiada, por cualquier medio o soporte y a través de cualquier procedimiento conocido o por conocer, que permita que una pluralidad de personas tenga acceso a dichos elementos, en las condiciones de copia y apropiación ya mencionadas (Echavarría, 2014).

Los prementados usos o actos de explotación comprenden, entre otros, la publicación, la enajenación, la divulgación o la inscripción en el registro oficial de la obra plagiada, los cuales, por el referido carácter público, deben implicar que dicha obra pueda ser conocida en las aludidas condiciones de copia y apropiación por una pluralidad de personas, por fuera de la órbita privada o doméstica (Rengifo, 1996).

Mientras la normativa en materia de derecho de autor no establezca elementos teleológicos típicos en relación con la infracción objeto de estudio, debe entenderse que la misma se configura con independencia de la finalidad perseguida por el plagiario, la cual puede ser de carácter económico, académico, profesional, social o de cualquier otro tipo.

De las definiciones propuestas se desprende que el denominado 'autoplagio' no hace parte de la materia de prohibición, ya que hay identidad entre el sujeto activo y el sujeto pasivo de la conducta de copia y, por lo tanto, no hay infracción de derecho alguno, ya que, en rigor, el titular originario de los derechos de autor usa su propia obra en otro contexto e indica que es el autor (y efectivamente lo es), lo cual desestima, por lo menos, el componente conductual de la apropiación.

En el caso del autoplagio, sin embargo, las conductas de copia y utilización pública pueden configurar otro tipo de infracciones a derechos patrimoniales de autor (cuando existe un titular derivado, por ejemplo, y aun así el autor copia y utiliza públicamente la obra, ejerciendo indebidamente derechos de los cuales, en virtud de una transferencia, ya no es el titular) o, inclusive, incumplimientos contractuales (como sucede cuando, a pesar de haberse comprometido convencionalmente a publicar una obra inédita, utiliza otra que ya había dado a conocer), pero ello, técnicamente, no constituye plagio.

Además de la realización concurrente de las tres conductas reseñadas, la comisión del plagio requiere el conocimiento real o potencial de la obra anterior ajena por parte del plagiario, para producir su obra posterior, sin el consentimiento previo y expreso del titular de los derechos de autor sobre la primera creación. 
En segundo lugar, se tiene que el plagio es un acto complejo desde sus consecuencias, dado que viola derechos tanto morales, como patrimoniales de autor, de ahí su carácter pluriofensivo respecto del contenido de tales derechos. En este sentido, el plagio comporta una vulneración de la naturaleza dual de estas prerrogativas, cuya concreción en un caso específico varía en función del tipo de plagio de que se trate (servil o inteligente) y de la vigencia de tales derechos al momento de la infracción; es decir, difieren según la obra se encuentre en el dominio privado o público.

Ergo, la copia puede traducirse en la violación de los derechos patrimoniales de reproducción y transformación y de los derechos morales de modificación e integridad; la apropiación, en la vulneración del derecho moral de paternidad, y la utilización, en la infracción de los derechos patrimoniales de comunicación pública y distribución y del derecho moral de inédito, de acuerdo con el contexto fáctico particular.

Ahora, si no se realizan de manera concurrente las tres conductas compositivas del plagio, no se configurará este acto complejo, sino, eventualmente, otro tipo de infracción: si el sujeto activo sólo se apropia, incurrirá en una omisión de autoría; si sólo copia, incurrirá en una reproducción no autorizada; y si sólo utiliza públicamente la obra preexistente y ajena, incurrirá en una comunicación pública (y/o distribución) no autorizada, según el caso.

\section{Tipificaciones penales del plagio}

Teniendo claro el concepto de plagio punible y sus contornos de ilicitud, se relacionan y analizan a continuación algunos de los tipos penales a través de los cuales se consagra y penaliza esta infracción a los derechos de autor en diversos ordenamientos jurídicos, en los cuales se regula penalmente esta conducta señalando ciertos verbos rectores o delegando su definición a la doctrina y a la jurisprudencia, al prever tautológicamente la acción típica de 'plagiar'.

\section{En Colombia.}

La regulación pertinente está contenida en los artículos 270 y 271 de la Ley 599 de 2000 (Código Penal), modificados por el artículo 14 de la Ley 890 de 2004:

Artículo 270. Violación a los derechos morales de autor. Incurrirá en prisión de treinta y dos (32) a noventa (90) meses y multa de veinte seis punto sesenta y seis (26.66) a trescientos (300) salarios mínimos legales mensuales vigentes quien:

1. Publique, total o parcialmente, sin autorización previa y expresa del titular del derecho, una obra inédita de carácter literario, artístico, científico, cinematográfico, audiovisual o fonograma, programa de ordenador o soporte lógico.

2. Inscriba en el registro de autor con nombre de persona distinta del autor verdadero, o con título cambiado o suprimido, o con el texto alterado, deformado, modificado o mutilado, o mencionando falsamente el nombre del editor o productor de una obra de carácter literario, artístico, científico, audiovisual o fonograma, programa de ordenador o soporte lógico. 
3. Por cualquier medio o procedimiento compendie, mutile o transforme, sin autorización previa o expresa de su titular, una obra de carácter literario, artístico, científico, audiovisual o fonograma, programa de ordenador o soporte lógico.

$[\ldots]$

Artículo 271. Violación a los derechos patrimoniales de autor y derechos conexos. Incurrirá en prisión de cuatro (4) a ocho (8) años y multa de veintiséis punto sesenta y seis (26.66) a mil (1.000) salarios mínimos legales mensuales vigentes quien, salvo las excepciones previstas en la ley, sin autorización previa y expresa del titular de los derechos correspondientes:

1. Por cualquier medio o procedimiento, reproduzca una obra de carácter literario, científico, artístico o cinematográfico, fonograma, videograma, soporte lógico o programa de ordenador, o, quien transporte, almacene, conserve, distribuya, importe, venda, ofrezca, adquiera para la venta o distribución, o suministre a cualquier título dichas reproducciones.

2. Represente, ejecute o exhiba públicamente obras teatrales, musicales, fonogramas, videogramas, obras cinematográficas, o cualquier otra obra de carácter literario o artístico.

3. Alquile o, de cualquier otro modo, comercialice fonogramas, videogramas, programas de ordenador o soportes lógicos u obras cinematográficas.

4. Fije, reproduzca o comercialice las representaciones públicas de obras teatrales o musicales.

5. Disponga, realice o utilice, por cualquier medio o procedimiento, la comunicación, fijación, ejecución, exhibición, comercialización, difusión o distribución y representación de una obra de las protegidas en este título.

6. Retransmita, fije, reproduzca o, por cualquier medio sonoro o audiovisual, divulgue las emisiones de los organismos de radiodifusión.

7. Recepcione, difunda o distribuya por cualquier medio las emisiones de la televisión por suscripción. (Cursivas ajenas al texto).

Como puede verse, sin perjuicio de la interpretación legislativa extensiva del órgano de cierre en materia penal (Corte Suprema de Justicia, Sentencia No. 31403 de 2010), los tipos penales que consagran los delitos contra los derechos morales y patrimoniales de autor no prevén de manera concurrente las tres conductas compositivas del plagio, razón por la cual es dable concluir que, en rigor, el plagio no está tipificado en el Código Penal colombiano.

\section{En Perú.}

La previsión legal consta en el artículo 219 del Decreto Legislativo 635 de 1991 (Código Penal), modificado por el artículo $1^{\circ}$ de la Ley 28.289 de 2004: 
Artículo 219. Plagio. Será reprimido con pena privativa de libertad no menor de cuatro ni mayor de ocho años y noventa a ciento ochenta días multa, el que con respecto a una obra, la difunda como propia, en todo o en parte, copiándola o reproduciéndola textualmente, o tratando de disimular la copia mediante ciertas alteraciones, atribuyéndose o atribuyendo a otro, la autoría o titularidad ajena. (Cursivas ajenas al texto).

El artículo transcrito comprende las conductas constitutivas del plagio a las cuales se ha hecho referencia, ya que 'difundir' es una forma de utilización pública, 'copiar' y 'reproducir' equivalen a la copia y 'atribuirse' se traduce en la apropiación. Es de anotar que esta norma establece que la infracción de usurpación de paternidad por falsa atribución a un tercero es una forma de plagio, razón por la cual la auto-atribución de la autoría de la obra plagiada no es un elemento constitutivo esencial de este fenómeno en la normativa peruana.

\section{En Ecuador.}

Está previsto en el artículo 324 de la Ley de Propiedad Intelectual (Codificación No. 2006-013):

Artículo 324. Serán reprimidos con prisión de tres meses a tres años y multa de mil trescientos catorce 45/100 (1.314,45) dólares de los Estados Unidos de América a trece mil ciento cuarenta y cuatro 50/100 (13.144,50) dólares de los Estados Unidos de América, tomando en consideración el valor de los perjuicios ocasionados, quienes en violación de los derechos de autor o derechos conexos:

$[\ldots]$

b) Inscriban, publiquen, distribuyan, comuniquen o reproduzcan, total o parcialmente, una obra ajena como si fuera propia (Cursivas ajenas al texto).

En este supuesto normativo, las acciones típicas concurren con la apropiación, pero no en todos los supuestos se configura el fenómeno del plagio, pues, aunque los actos de utilización consistentes en 'inscribir', 'publicar', 'distribuir' y 'comunicar' (en concurso, se insiste, con la usurpación) presuponen la copia, no ocurre lo mismo con la simple reproducción, evento en el cual falta la última conducta necesaria para que se estructure el plagio punible, de conformidad con la definición propuesta en el acápite precedente.

\section{En Bolivia.}

Se remite al artículo 362 del Decreto Ley 10.426 de 1972 (Código Penal), modificado por el artículo 2 de la Ley 1768 de 1997:

Artículo 362. Delitos contra la propiedad intelectual. Quien con ánimo de lucro, en perjuicio ajeno, reproduzca, plagie, distribuya, publique en pantalla o en televisión, en todo o en parte, una obra literaria, artística, musical, científica, televisiva o cinematográfica, o su transformación, interpretación, ejecución artística a través de cualquier medio sin la autorización de los titulares de los derechos de propiedad 
intelectual o de sus concesionarios o importe, exporte o almacene ejemplares de dichas obras, sin la referida autorización, será sancionado con la pena de reclusión de tres meses a dos años y multa de sesenta días. (Cursivas ajenas al texto).

En el enunciado normativo recién transcrito, se tipifica la conducta de plagio condicionándola al ánimo de lucro del agente y empleando como verbo rector la expresión a través de la cual se identifica este comportamiento, razón por la cual, ante la ausencia de definición legal, le corresponde a la doctrina y a la jurisprudencia describir y precisar los contornos fácticos de esta infracción.

\section{En Venezuela.}

Se prevé en los artículos 119, 120 y 122 de la Ley sobre el Derecho de Autor:

Artículo 119. Siempre que el hecho no constituya un delito más grave previsto en el Código Penal u otras leyes, será castigado con prisión de seis (6) a dieciocho (18) meses, todo aquel que con intención y sin tener derecho a ello, emplee el título de una obra, con infracción del artículo 24; o comunique, en violación del artículo 40 de esta Ley, en forma original o elaborada, íntegra o parcialmente, obras del ingenio, ediciones de obras ajenas o de textos, o fotografías o productos obtenidos por un procedimiento similar a la fotografía o imágenes impresas en cintas cinematográficas, equiparadas a la fotografía; o distribuya, en violación del primero o segundo apartes del artículo 41, ejemplares de obras del ingenio protegidas por esta Ley, inclusive de ejemplares de fonogramas; o retransmita, con infracción del artículo 101, una emisión de radiodifusión sin el consentimiento del titular del respectivo derecho.

Artículo 120. Será penado con prisión de uno a cuatro (4) años, todo aquel que con intención y sin derecho reproduzca, con infracción del encabezamiento del artículo 41 de esta Ley, en forma original o elaborada, íntegra o parcialmente, obras del ingenio, ediciones de obras ajenas o de textos, o fotografías o productos obtenidos por un procedimiento similar a la fotografía o imágenes impresas en cintas cinematográficas equiparadas a la fotografía; o quien introduzca en el país, almacene, distribuya, venda o ponga de cualquier otra manera en circulación reproducciones ilícitas de las obras del ingenio o productos protegidos por esta ley.

Artículo 122. Las penas previstas en los artículos precedentes se aumentarán en la mitad cuando los delitos señalados sean cometidos respecto de una obra, producto o producción no destinados a la divulgación, o con usurpación de paternidad, o con deformación, mutilación u otra modificación de la obra, producto o producción que ponga en peligro su decoro o la reputación de una de las personas protegidas por la Ley. (Cursivas ajenas al texto).

Los verbos rectores resaltados en la cita precedente se compadecen con los elementos indicados como constitutivos del plagio en el concepto propuesto en el primer apartado de este escrito. Sin embargo, no en todos los supuestos concurren los tres elementos que estructuran el plagio, conforme a dicha noción, como es el caso de la simple 'reproducción' 'con usurpación de paternidad', en el cual se echa de menos la utilización pública. 


\section{En Argentina.}

El ordenamiento argentino remite al artículo 72 de la Ley 11.723 de 1933 (Régimen legal de la propiedad intelectual):

Artículo 72. Sin perjuicio de la disposición general del artículo precedente, se consideran casos especiales de defraudación y sufrirán la pena que él establece, además del secuestro de la edición ilícita:

c) El que edite, venda o reproduzca una obra suprimiendo o cambiando el nombre del autor, el título de la misma o alterando dolosamente su texto (Cursivas ajenas al texto).

$\mathrm{Al}$ respecto, es pertinente anotar - de conformidad con el concepto propuestoque la reproducción y la usurpación no configuran, por sí mismas, el fenómeno del plagio, por lo que el tercer supuesto no estructura esta forma especial infracción, sino un concurso de violaciones individuales. Además, es de advertir que la 'supresión' y 'cambio' del autor bastarán para constituir una apropiación si se circunscriben a las modalidades en que esta puede presentarse.

\section{En México.}

La norma pertinente es el artículo 427 del Código Penal Federal de los Estados Unidos Mexicanos:

Artículo 427. Se impondrá prisión de seis meses a seis años y de trescientos a tres mil días multa, a quien publique a sabiendas una obra substituyendo el nombre del autor por otro nombre. (Cursivas ajenas al texto).

En la disposición referida se circunscribe la utilización pública a la acción típica de publicación, por lo que las demás formas de uso público quedan por fuera del espectro del tipo penal. Atendiendo los límites conceptuales de la noción propuesta, el nombre por el cual se sustituye el del autor debe ser el del agente, si no es así, no se configurará un plagio, sino una usurpación de paternidad por falsa atribución a un tercero.

\section{En Chile.}

Se remite a los artículos 79 y 81 de la Ley 17.336 de 1970 (Ley sobre Propiedad Intelectual):

Artículo 79. Cometen delito contra la propiedad intelectual y serán sancionados con la pena de presidio menor en su grado mínimo y multa de 5 a 50 unidades tributarias mensuales:

$[\ldots]$

c) Los que falsifiquen obras protegidas por esta ley, sean literarias, artísticas o científicas, o las editen, reproduzcan o vendan ostentando falsamente el nombre del 
editor autorizado, suprimiendo o cambiando el nombre del autor o el título de la obra, o alterando maliciosamente su texto

Artículo 81. El que a sabiendas publicare o exhibiere una obra perteneciente al patrimonio cultural común bajo un nombre que no sea el del verdadero autor, será penado con una multa de dos a cuatro sueldos vitales anuales, escala A), del departamento de Santiago. (Cursivas ajenas al texto).

De los anteriores artículos se desprende que el plagio se configura, aunado con la apropiación, en los supuestos de 'venta' , 'publicación' y 'exhibición' (que consisten en usos públicos, que presuponen la copia); eventualmente se estructurará en la 'edición', de conformidad con la acepción que se atribuya a esta acción típica, y, en relación con la mera 'reproducción', ya se ha dicho que esta no comporta un uso público y, por ende, tampoco un plagio, según la definición propuesta.

Es del caso traer a colación el comentario reseñado en punto de la legislación argentina, relativo a las condiciones necesarias para que los eventos de 'supresión' y 'cambio' configuren una apropiación y, en el mismo sentido, se anota que el nombre bajo el cual se 'publica' o 'exhibe' la obra - que está en el dominio público- debe ser el del plagiario, pues, de no ser así, se estará ante el supuesto de usurpación de paternidad por falsa atribución a un tercero.

\section{En Uruguay.}

Lo atinente a la materia de análisis se encuentra previsto en el artículo 46 de la Ley 9.739 de 1937 (Ley sobre Derechos de Autor), modificado por la Ley 17.616 de 2003:
Artículo 46. A) El que edite, venda, reproduzca o hiciere reproducir por cualquier medio o instrumento -total o parcialmente-; distribuya; almacene con miras a la distribución al público, o ponga a disposición del mismo en cualquier forma o medio, con ánimo de lucro o de causar un perjuicio injustificado, una obra inédita o publicada, una inter- pretación, un fonograma o emisión, sin la autorización escrita de sus respectivos ti- tulares o causahabientes a cualquier título, o se la atribuyere para sí o a persona distinta del respectivo titular, contraviniendo en cualquier forma lo dispuesto en la presente ley, será castigado con pena de tres meses de prisión a tres años de penitenciaría". (Cursivas ajenas al texto).

Entendiendo que los verbos rectores relevantes son los subrayados en la cita que antecede, es de anotar que, tal como se puntualizó en casos anteriores, la 'edición' y la 'reproducción' suponen ciertas salvedades en relación con el plagio y que la atribución a persona distinta no es una apropiación, sino un evento de usurpación de paternidad por falsa atribución a un tercero.

\section{En España.}

Se encuentra prevista en el artículo 270 de la Ley Orgánica 10/1995 (Código Penal): 
Artículo 270. 1. Será castigado con la pena de prisión de seis meses a dos años y multa de 12 a 24 meses quien, con ánimo de lucro y en perjuicio de tercero, reproduzca, plagie, distribuya o comunique públicamente, en todo o en parte, una obra literaria, artística o científica, o su transformación, interpretación o ejecución artística fijada en cualquier tipo de soporte o comunicada a través de cualquier medio, sin la autorización de los titulares de los correspondientes derechos de propiedad intelectual o de sus cesionarios". (Cursivas ajenas al texto).

En este enunciado normativo, el legislador español tipifica penalmente la conducta de plagio a través de un verbo rector tautológico, que no describe ni define la acción típica, sino que la nombra, y, además, condiciona la punición de este comportamiento al ánimo de lucro y a la producción de un perjuicio a una tercera persona (en principio, el titular de los derechos vulnerados).

\section{En Francia.}

La definición legal se encuentra prevista en los artículos L-335-2 (modificado por el artículo 4 de la Ley 2007-1544) y L335-3 (modificado por el artículo 8 de la Ley 2009-669) del Código de la Propiedad Intelectual, en relación con el delito de falsificación (contrefaçon):

Article L.335-2. Toute édition d'écrits, de composition musicale, de dessin, de peinture ou de toute autre production, imprimée ou gravée en entier ou en partie, au mépris des lois et règlements relatifs à la propriété des auteurs, est une contrefaçon et toute contrefaçon est un délit.

La contrefaçon en France d'ouvrages publiés en France ou à l'étranger est punie de trois ans d'emprisonnement et de 300000 euros d'amende.

Seront punis des mêmes peines le débit, l'exportation et l'importation des ouvrages contrefaisants.

Article L.335-3. Est également un délit de contrefaçon toute reproduction, représentation ou diffusion, par quelque moyen que ce soit, d'une oeuvre de l'esprit en violation des droits de l'auteur, tels qu'ils sont définis et réglementés par la loi.

Est également un délit de contrefaçon la violation de l'un des droits de l'auteur d'un logiciel définis à l'article L.122-6. (Ley número 92-597, 1992)

Como puede verse, en la legislación francesa las infracciones a la propiedad intelectual se agrupan como falsedades y no se regula específicamente la conducta constitutiva de plagio, la cual, por ende, sólo es punible "si se vuelve tan grave que llega a cambiar de nombre y cae entonces en un delito de falsificación ('contrefaçon')"' (Renouard, 1838, citado por Nettel, 2013).

\section{En Italia.}

Debe consultarse el artículo 171 de la Ley 633 de 1941 (Ley sobre Derecho de Autor), modificado por el Decreto Ley 64 de 2010: 
Articolo 171. Salvo quanto disposto dall'art. 171-bis e dall' articolo 171-ter è punito con la multa da euro 51 a euro 2.065 chiunque, senza averne diritto, a qualsiasi scopo e in qualsiasi forma:

a) riproduce, trascrive, recita in pubblico, diffonde, vende o mette in vendita o pone altrimenti in commercio un'opera altrui o ne rivela il contenuto prima che sia reso pubblico, o introduce e mette in circolazione nello Stato esemplari prodotti all'estero contrariamente alla legge italiana;

a-bis) mette a disposizione del pubblico, immettendola in un sistema di reti telematiche, mediante connessioni di qualsiasi genere, un'opera dell'ingegno protetta, o parte di essa;

b) rappresenta, esegue o recita in pubblico o diffonde, con o senza variazioni od aggiunte, un'opera altrui adatta a pubblico spettacolo od una composizione musicale. La rappresentazione o esecuzione comprende la proiezione pubblica dell'opera cinematografica, l'esecuzione in pubblico delle composizioni musicali inserite nelle opere cinematografiche e la radiodiffusione mediante altoparlante azionato in pubblico;

c) compie i fatti indicati nelle precedenti lettere mediante una delle forme di elaborazione previste da questa legge;

$[\ldots]$

f) in violazione dell'art. 79 ritrasmette su filo o per radio o registra in dischi fonografici o altri apparecchi analoghi le trasmissioni o ritrasmissioni radiofoniche o smercia i dischi fonografici o altri apparecchi indebitamente registrati.

$[\ldots]$

La pena è della reclusione fino ad un anno o della multa non inferiore a euro 516 se $\mathrm{i}$ reati di cui sopra sono commessi sopra una opera altrui non destinata alla pubblicità, ovvero con usurpazione della paternità dell'opera, ovvero con deformazione, mutilazione o altra modificazione dell'opera medesima, qualora ne risulti offesa all' onore od alla reputazione dell'autore. (Cursivas ajenas al texto) (Ley número 633, 1941)

De igual forma, se anota que en los supuestos en que la conducta no comporte una utilización pública, que presuponga la copia, no se configura el fenómeno de plagio, como es el caso de la 'reproducción' y la 'transcripción'. Además, es menester precisar que la usurpación de la paternidad, para que se traduzca en una apropiación, debe consistir en una auto-atribución a través de una cualquiera de las tres modalidades especificadas en la noción sugerida.

\section{Propuesta del supuesto de hecho del tipo penal de plagio}

Dado que la mayoría de los legisladores (particularmente, los referidos en el acápite precedente) han estimado que el plagio es una de las infracciones más graves contra uno de los bienes jurídico-penales más importantes (cuales son los derechos de autor), corresponde ahora precisar el supuesto de hecho que permita 
tipificar penalmente esta conducta compleja de manera técnica y comprensiva, de conformidad con la noción presentada en el primer acápite de este escrito.

Para el efecto, se describen a continuación los elementos específicos del tipo penal de plagio que se propone, cuales son -en lo que mira con la cara objetiva de la descripción típica- el bien jurídico penal protegido, el sujeto activo, el sujeto pasivo, la conducta y -en relación con el componente interno del comportamiento objeto de prohibición- el dolo, para finalizar con la formulación del supuesto de hecho del tipo penal, que describa, en rigor, el fenómeno del plagio.

En primer lugar, se tiene que el bien jurídico penalmente tutelado son los derechos de autor, ya que -como bien se anticipó- el plagio consiste, ante todo, en una infracción a las prerrogativas que se le conceden originariamente al autor sobre su obra, las cuales son violadas en su completitud (de ahí la característica de acto complejo propia del plagio), en la medida en que se vulnera la naturaleza dual de su contenido, sin que por ello se desvirtúe la unicidad de la categoría jurídica de los derechos de autor, como bien jurídico afectado, y el carácter monoofensivo del tipo penal.

En consideración al prealudido bien jurídico, se trata de un tipo penal de lesión, ya que a partir de la realización de la acción típica, el bien jurídico penal de los derechos de autor resulta menoscabado. Ahora, es importante diferenciar el aludido bien jurídico del objeto material real de este tipo penal, el cual se concreta en los elementos originales de expresión (copiados, apropiados y usados públicamente) de la obra plagiada por el sujeto activo.

En segundo lugar, se tiene que el sujeto activo o agente es el plagiario, es decir, la persona que copia, se apropia y usa públicamente la obra y, en consecuencia, vulnera los derechos de autor que recaen sobre dicha creación intelectual. Es de anotar que el plagio admite las distintas formas de concurso de personas, cuales son la autoría material, la coautoría, la autoría mediata, la determinación y la complicidad.

Es preciso acotar que el plagiario no debe reunir unas calidades especiales para poder llevar a cabo la conducta típica, sino que la misma puede ser realizada por cualquier persona; en consecuencia, el sujeto activo del plagio es común. Más aún, dado que no es necesaria la intervención de varias personas a título de sujeto activo, el tipo penal de plagio es de los llamados 'monosubjetivos'.

Ahora, el hecho de que el autor sea coautor de la obra posterior que materializa el plagio (por haber realizado un aporte creativo distinto de los elementos originales plagiados), no hace que el sujeto activo sea calificado por esa condición de creador, ya que, respecto del objeto material de la conducta punible (esto es, la obra ajena y preexistente), este no es -ni puede ser- autor.

En tercer lugar, se tiene que el sujeto pasivo del delito de plagio es el titular de los derechos de autor infringidos, en tanto titular del bien jurídico penalmente 
tutelado. Dada la naturaleza dual de los derechos de autor, es posible que el titular de los derechos morales de autor (que siempre es el creador) sea diferente del titular de los derechos patrimoniales de autor (en virtud de una transferencia), por lo que es factible que el bien jurídico penal en este caso tenga titulares diversos.

En cuarto lugar, la acción típica del plagio (como ya se precisó) supone la realización de tres diversos comportamientos de forma concurrente: la copia, la apropiación y la utilización pública. En tal virtud, el tipo penal de plagio es un tipo compuesto, dado que describe tres diversas conductas que constituyen, por sí mismas, una descripción típica autónoma y que deben realizarse de manera cumulativa para que se pueda predicar la tipicidad de un determinado comportamiento.

En relación con las conductas de copia y utilización pública descritas en precedencia, es evidente la procedencia de un elemento modal individualizante, en virtud del cual tales comportamientos deben llevarse a cabo "sin autorización previa y expresa del titular de los derechos de autor correspondientes" (Rincón y Naranjo, 2012), pues, si se cuenta con la aquiescencia del sujeto pasivo para realizar dichas conductas, no se estarán infringiendo las prerrogativas respectivas; específicamente, las de contenido patrimonial, por cuanto las de contenido moral -no puede olvidarse- son inalienables.

Al hilo de lo anterior, es dable concluir, en punto de clasificación, que el tipo penal de plagio es de comisión, en tanto describe la acción prohibida en las hipótesis de copia, uso público, apropiación mediante la auto-atribución de autoría directa y apropiación a través de la mención incidental o genérica. La conducta de apropiación por omisión de paternidad con usurpación de autoría, empero, sugiere, como su nombre lo indica, una omisión.

Adicionalmente, es un tipo penal de conducta instantánea, dado que la realización de los comportamientos se agota en un solo instante y no se renueva de manera permanente en el tiempo, y de resultado, ya que a la conducta compleja arriba descrita le sigue un efecto en el mundo fenomenológico consistente en la copia, la apropiación y la utilización pública de la obra ajena y preexistente. Tales resultados, en los términos referidos con antelación, se deben producir de manera concurrente.

En quinto lugar, el tipo penal de plagio es doloso, lo que implica que el agente tiene la consciencia y la voluntad de realizar los hechos materia de prohibición. Por ende, la acción típica constitutiva del plagio supone un componente cognoscitivo (el conocimiento o saber) y otro volitivo o conativo (la voluntad de realizar los elementos objetivos del tipo), por parte del sujeto activo del delito.

Finalmente, es de anotar que el elemento relativo a la obtención de un provecho de cualquier tipo (económico, académico u otro) por parte del infractor, derivado de la realización de la conducta punible, no parece ser una circunstancia esencial 
para la configuración del plagio, pues el bien jurídico protegido no es el patrimonio económico o la integridad moral, sino los derechos de autor.

Con base en lo hasta aquí expuesto, se concreta y explicita ahora una solución de tipicidad para consagrar el fenómeno del plagio, en consonancia con los postulados de la propiedad intelectual y del derecho penal, de conformidad con el concepto de 'plagio punible' sugerido y considerando las fórmulas legislativas propuestas en diferentes países para regular penalmente esta infracción -grave y particular- al bien jurídico de los derechos autor.

Al efecto, se estima necesario servirse de términos comprensivos de las diferentes modalidades en las que el plagio puede presentarse, razón por la cual se emplean locuciones amplias como la 'utilización pública' (que incluye todo tipo de usos conocidos o por conocer), en lugar de enlistar (taxativamente, en virtud del principio de tipicidad) algunas especies de este género (como 'publicar', 'divulgar', 'inscribir', 'distribuir' o 'comunicar') y dejar así en la impunidad otras manifestaciones del plagio que no se contemplen de manera expresa, pero que son igualmente lesivas del bien jurídico penalmente tutelado, que quedaría, de esta forma, expósito.

De ahí que, igualmente, se recurra al término 'copiar' como verbo rector, para acoger la definición tradicional del fenómeno del plagio y para describir, a su vez, todas las formas en que esta conducta pueda materializarse (a través de una reproducción o una transcripción, por ejemplo). Asimismo, se hace necesario valerse de la noción amplia de la 'apropiación' para conglobar las modalidades de indicación del sujeto activo como autor, de la mención incidental o genérica del creador legítimo y de omisión de paternidad con usurpación de autoría, dentro de la descripción típica planteada.

Esta es, entonces, la propuesta: Plagio. El que copie, de manera literal o simulada, uno o más elementos originales de una obra ajena protegida por derecho de autor y se atribuya la autoría de los mismos, incurrirá, si los utiliza públicamente, en... (sanción penal).

De esta forma, con las previsiones anteriores, la propuesta de lege ferenda del tipo penal de plagio que se presenta se corresponde con la lesividad y la relevancia atribuida a esta infracción e incorpora las plurales y diversas formas en que el plagio se realiza, partiendo de un concepto de 'plagio punible' restrictivo, que filtra los comportamientos atentatorios para punir sólo aquellos que afectan los derechos de autor de la manera más grave e intolerable.

\section{Referencias}

Antequera, R. (2012). Derechos intelectuales y derecho a la imagen en la jurisprudencia comparada. Madrid: Editorial REUS S.A. 
Echavarría, M. A. (2014). ¿Qué es el plagio? Propuesta conceptual del plagio punible. Revista Facultad de Derecho y Ciencias Políticas, 121 (44), 699-720.

Estados Unidos Mexicanos. Código Penal Federal (1931). Cámara de Diputados del H. Congreso de la Unión, agosto de 1931.

Estado Plurinacional de Bolivia. Ley 1768 de 1997. De modificaciones al Código Penal. Gaceta Oficial No. 1984. Congreso Nacional, marzo de 1997.

Ley 599 de 2000. Por la cual se expide el Código Penal. Diario Oficial No. 44.097. Congreso de la República, julio de 2000.

Nettel, A. L. (2013). Derecho de autor y plagio. Alegatos, (83), 135-152.

Reino de España. Ley Orgánica 10 de 1995. Código Penal. BOE No. 281. Congreso de los Diputados, noviembre de 1995.

Rengifo, E. (1996). El moderno derecho de autor. Bogotá: Universidad Externado de Colombia.

República de Argentina Ley 11.723 de 1933. Régimen Legal de Propiedad Intelectual. Boletín Oficial No. 11.793. Congreso argentino, septiembre de 1933.

República de Chile. Ley 17.336 de 1970. Sobre Propiedad Intelectual. Diario Oficial de Chile, Congreso Nacional, octubre de 1970.

República del Ecuador. Codificación No. 2006-013. Ley de propiedad intelectual. Registro Oficial No. 426. Congreso Nacional, noviembre de 2006.

República del Perú. Decreto Legislativo No. 635 de 1991. Por el que se promulga el Código Penal. Congreso de la República, abril de 1991.

República Francesa. Ley 92-597 de 1992. Sobre el Código de la Propiedad Intelectual. Diario Oficial No. 153. Parlamento francés, julio de 1992.

República Italiana. Ley 633 de 1941. Sobre la Protección del Derecho de Autor y los Derechos Conexos. Parlamento italiano, abril de 1941.

República Oriental de Uruguay. Ley 17.616 de 2003. Ley de Derecho de autor y Derechos Conexos. Diario Oficial No. 26.179. Parlamento de Uruguay, enero de 2003.

República de Venezuela. Ley sobre el Derecho de Autor. Gaceta Oficial No. 4.638. Congreso de la República, octubre de 1993.

Rincón, J. y Naranjo, V. (2012). Delito informático electrónico de las telecomunicaciones $y$ de los derechos de autor. Bogotá: Grupo Editorial Ibáñez.

Sentencia 31403 (2010, mayo 28). Casación. M. P. Sigifredo Espinosa Pérez. Sala de Casación Penal, Corte Suprema de Justicia. 
Vitruvio, M. (1997). Los diez libros de Arquitectura. (Trad. J. L. Oliver). Madrid: Alianza Editorial S.A. Recuperado de: http://es.scribd.com/doc/48058991/ Vitruvio-Polion-Marco-Los-Diez-Libros-De-Arquitectura. (Obra originalmente publicada en 1649). 